\title{
Analysis of a Photovoltaic Generator as a Means of Compensation in a Low Voltage Network
}

\author{
Nacer Mahfoudi, Hocine Labar \\ Department of Electrical Engineering, Badji Mokthar University of Annaba, Annaba, Algeria
}

Email address:

Mahfoudi.Nacer@yahoo.fr (N. Mahfoudi)

\section{To cite this article:}

Nacer Mahfoudi, Hocine Labar. Analysis of a Photovoltaic Generator as a Means of Compensation in a Low Voltage Network. International Journal of Energy and Power Engineering. Vol. 6, No. 5, 2015, pp. 75-83. doi: 10.11648/j.ijepe.20170605.12

Received: April 13, 2015; Accepted: June 12, 2015; Published: November 10, 2017

\begin{abstract}
The photovoltaic applications are no longer limited to their use in remote sites. The current trend, particularly in industrialized countries is connected to the power grid individual installations, especially collective facilities and projects in the courtyard of this century will surely change our energy consumption habits. As part of this work we considered the use of mini photovoltaic plants connected to the low voltage grid as a means of compensation, generating electricity at the point of deficit. For this we analyzed the behavior of a MV / LV, which has voltage drops in two starts and tried to connect at the end of each starting of a photovoltaic mini plant in order to bring the network technical parameters (power voltage) in permissible limits.
\end{abstract}

Keywords: Decentralized Production, Photovoltaic Conversion, System Voltage Drops, Network Low-Voltage

\section{Introduction}

This study was done in order to address the problem of the voltage drop in our low voltage networks and proposes a new technical and economic approach. The power quality provided to users depends on the voltage at the delivery point. The improvement of the technical parameters (voltage -current) is a preoccupation of the electricity distributor. Among the means currently used, we cite the strengthening of conductor cross sections, creation of new posts MV / LV transformers... etc. But the current trend towards a certain decentralization of electricity production is likely to increase due to the maturing of new means of transformation of primary energy [1]. Connecting the mini photovoltaic plants in low voltage electrical network can solve this problem by producing connected mini photovoltaic plants in low voltage, It is with this objective that this work is undertaken. We took a real case of how a low-voltage network which has voltage drops at these ends; customers connected to this position are underserved. Subsequently, we studied the impact of the connection of photovoltaic energy on the parameters of the network. The different concepts of solar cell technology take us to the development of the theoretical model to a diode [2], the main characteristics under different illumination and temperatures have been developed by simulation in Matlab. Finally We present the main experimental results, simulation, and conclusion of future work.

\section{Characteristics of Low Voltage Network Study}

The distribution low voltage network (LV) is operated by three different departures. It supplies more than 348 subscribers, the majority are connections by 02 filaments $(220 \mathrm{~V})$. The general characteristics of the network are given in Table 1.

Table 1. Characteristics of the LV Network.

\begin{tabular}{|c|c|c|c|c|c|}
\hline Departure & Length & Section(mm2) & Voltage drop (\%) & Number of connection $(220 \mathrm{v})$ & Number of connection $(380 \mathrm{v})$ \\
\hline $\mathrm{N}^{\circ} 1$ & 1289 & 70 & 13.76 & 135 & 22 \\
\hline $\mathrm{N}^{\circ} 2$ & 802 & 48 & 14.81 & 112 & 16 \\
\hline $\mathrm{N}^{\circ} 3$ & 453 & 17 & 2.79 & 55 & 8 \\
\hline
\end{tabular}


Transformers often appear as interfaces in networks of different voltage levels; in our case it is a three-phase transformer used to go from $30 \mathrm{kV}$ (HV) $400 \mathrm{~V}$ (LV).

To calculate the imbalance coefficients (Kdes) and $(\mathrm{Ku})$ use, you must determine the average current produced by the transformer.

With:

$$
\begin{gathered}
I_{M E D}=\frac{I_{1}+I_{2}+I_{3}}{3} \\
K_{d e s}=\frac{\left(I_{M E D}-I_{p h}\right)}{I_{M E D}} \cdot 100 \\
K_{U}=\frac{I_{M E D}}{I_{N O M}}
\end{gathered}
$$

For our network and with the monitoring and measuring equipment (Metrel power) is determined I1; I2; I3 Table 2. We get: $\mathrm{Kdes}=13.97 \%$ and $\mathrm{KU}=93.77 \%$.

Technical parameters of the network

It is noted from Table 1 that the values of the voltage drop departures 1 and 2 exceed the permissible limits. Attempts are made to bring the technical parameters of the network (current-voltage) to the standard set by [2], by producing photovoltaic energy in the deficit area.

Table 2. Values of currents measurement.

\begin{tabular}{lllllll}
\hline & 12:45:00 & 12:47:00 & 12:49:00 & 12:51:00 & 12:53:00 & 12:55:00 \\
\hline I1MAX(A) & 279.60 & 271.80 & 271.80 & 262.80 & 278.70 & 269.10 \\
I2MAX(A) & 265.80 & 275.40 & 285.00 & 289.20 & 298.50 & 289.20 \\
I3MAX(A) & 263.10 & 264.60 & 273.60 & 270.30 & 267.30 & 263.70 \\
\hline
\end{tabular}

\section{Description of the System Proposed}

The proposed conversion chain is constituted by a photovoltaic generator, a prescaler formed by a chopper (buck -boost), which acts as an interface between the source and the load a three-phase inverter-type Neutral-Point-Clamped (NPC) at three levels, its control based on pulse with modulation (PWM) which aims to have a closest output voltage of the sine wave. The general approach for the design and energy transfer of management on the basis of actual forecasted consumption and the measurement site meteorological data is shown in Figure 1.

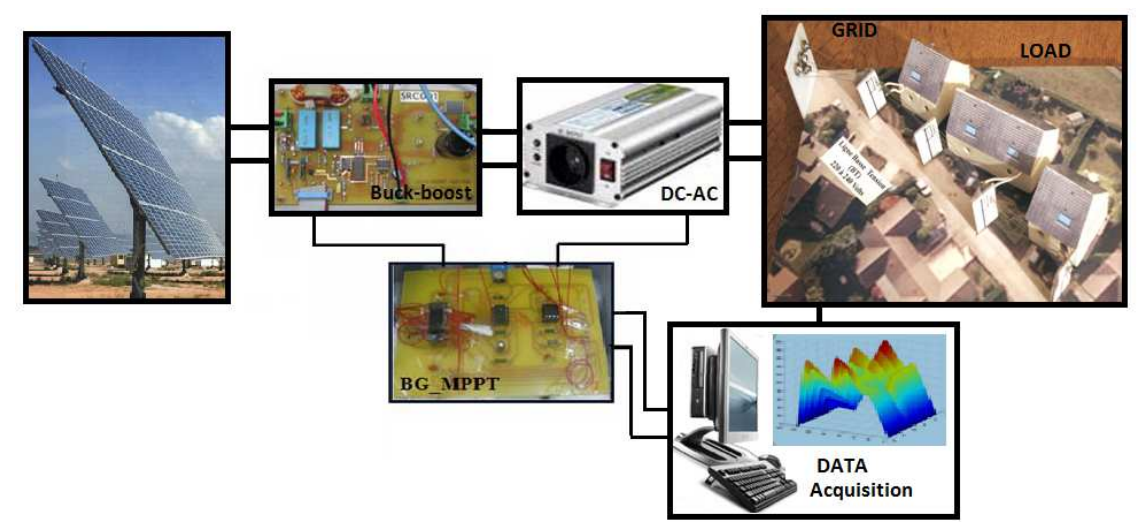

Figure 1. Architecture of system proposed.

\section{Model of the Photovoltaic Cell}

The photovoltaic cell allows the direct conversion of light energy into electrical energy. It is often presented, as a current generator power is equivalent to a power source that is shunted by a diode [3]. To take account of the physical phenomena at the level of the cell; the model is completed by serie (rs) and shunt (rp) resistances figure 2 .

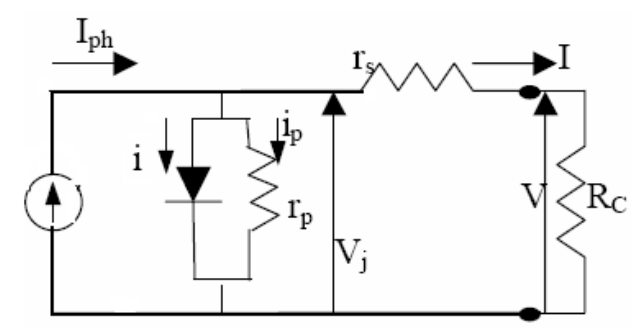

Figure 2. Equivalent circuit model of a photovoltaic cell.
The current I provided by the photovoltaic cell figure 2 is given by $(3,4)$.

$$
I=I_{P h}-i-i_{P}=I_{P h}-I_{S}\left[e^{\left(\frac{q V_{J}}{K T}\right)}-1\right]-\frac{V_{J}}{r_{p}}
$$

Substituting VJ instead VJ $=\mathrm{V}+\mathrm{rs}$. I we get:

$$
I=I_{P h}-I_{S}\left[e^{\left(q\left(\frac{\left.V+r_{S} \cdot I\right)}{K T}\right)\right.}-1\right]-\frac{V+r_{S} \cdot I}{r_{p}}
$$

With:

$\mathrm{I}_{\mathrm{Ph}}$ : photo current; K: Boltzmann constant.

$\mathrm{T}$ : temperature of the cell; $\mathrm{V}$ : voltage at the terminals of the cell; q: electron charge. $i_{\mathrm{p}}$ : current derived by the shunt resistance; $i_{S}$ : current derived by the series resistance. $r_{S}$ : series resistance due to the contribution of the resistances base and the front of the junction. 
$\mathrm{r}_{\mathrm{P}}$ : shunt resistance is a consequence of the state's surface along the periphery of the cell.

In order to obtain a generalized mathematical model of a GPV all losses caused by the combination of panels in series and in parallel are included, which provides the following equation:

$$
I=N_{P} I_{P h}-N_{P} I_{S}\left[e \frac{\left(N_{S} V+r_{S} I\left(\frac{N_{S}}{N_{P}}\right)\right)}{N_{S} K T}-1\right]-\frac{N_{S} V+r_{S} I\left(\frac{N_{S}}{N_{P}}\right)}{r_{p}\left(\frac{N_{S}}{N_{P}}\right)}(6)
$$

Np: Number of panel connected in parallel. Ns: Number of panel connected in series.

The characteristic I (V) Figure 3 is plotted from the equation 4 . This is an implicit equation whose solution $\mathrm{I}=\mathrm{f}(\mathrm{V})$ uses successive approximation methods [5]. We identified two major points within the curve. The short-circuit current, when $\mathrm{V}=0$, is $\mathrm{I}=\mathrm{Iph}$.

The open circuit voltage, when $\mathrm{I}=0$, is written:

$$
V c o=\frac{K T}{q \cdot \log \left[\frac{I_{P h}}{I_{S}}+1\right]}
$$

The search algorithm (MPPT) may be more or less complex depending on the type of implant chosen and desired performance. In the literature we can find different types of controls algorithms with more information, in our case, we have chosen the optimization technique by Algorithm Hill Climbing, which is to "mount" the operating point along the characteristic, Figure 4, of the generator. For this, two slopes are possible. The search is theoretically stopped when the maximum power point is reached.

This method is based on the relationship between the power panel and the value of the duty cycle applied to the converter. Mathematically, the maximum power point is reached when $\mathrm{dPPV} / \mathrm{d} \alpha$ is forced to zero by the command, by judicious choice of the duty cycle $\alpha$. The variable Slope, Figure 5, corresponds to a variable that is "1" or value "-1" in the direction that we should give research to increase the power output of the panel.

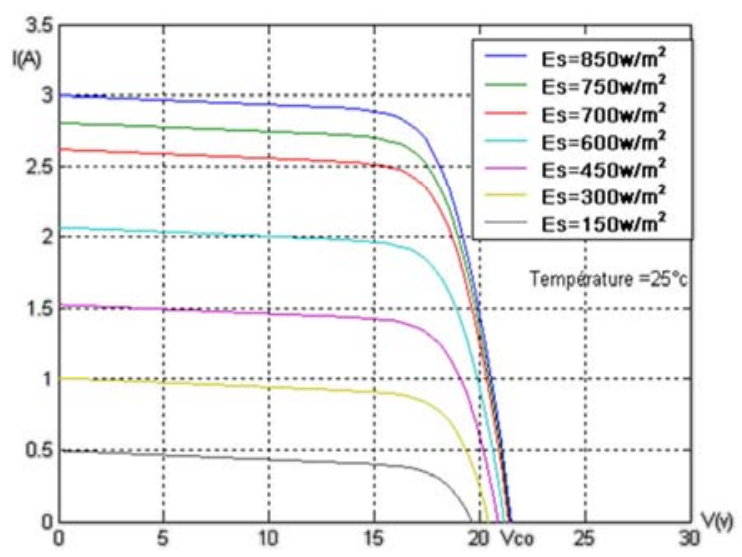

Figure 3. Caracteristic I (V) of GPV in different insolation.

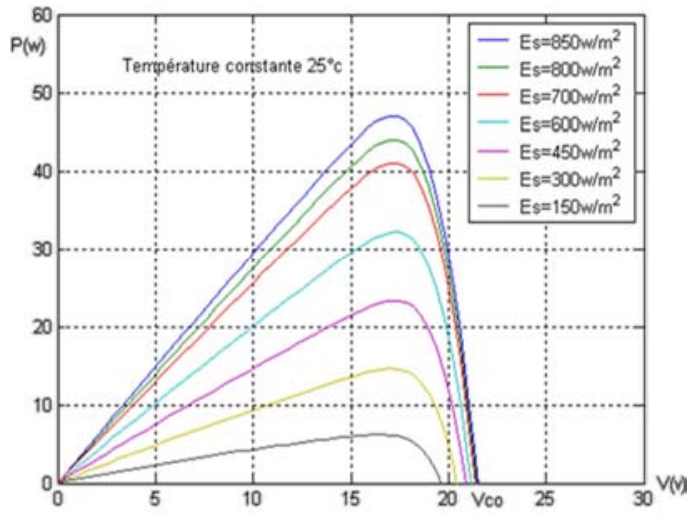

Figure 4. Caracteristic I (V) of GPV in different insolation.

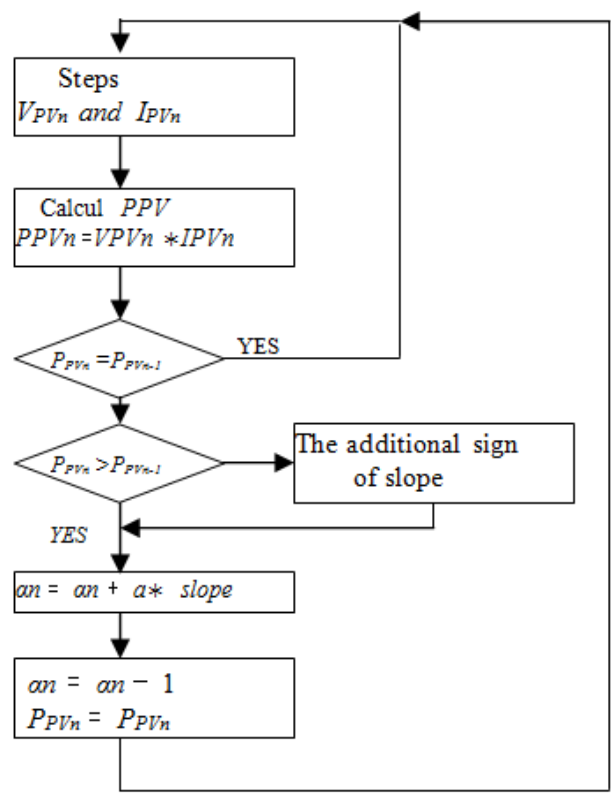

Figure 5. Algorithm type the command Hill Climbing.

\section{Model of the Converter (Buck Boost)}

Figure 6. corresponds to a DC-DC converter "Buck -Boost" which is used as a source adapter load, when the power supply to the load is greater or less than that delivered by the PV generator (4). The adaptation between the source and the load is performed by varying the duty cycle $\alpha$. The chopper output voltage depending on the input voltage and the duty ratio is expressed by the following expression:

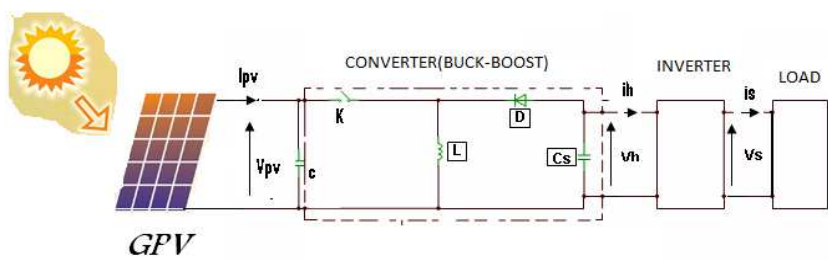

Figure 6. Buck-Boost converter model.

$$
V_{S}=\frac{\alpha}{1-\alpha} V_{P V}
$$


If it takes account of the internal resistance of the coil becomes the equation:

$$
V_{S}=\frac{V_{P V} \alpha}{(1-\alpha)\left[1+\frac{R_{B}}{R(1-\alpha)^{2}}\right]}
$$

\section{Model of the Inverter}

The structure of the three-phase bridge voltage inverter type 3 -level NPC is represented by Figure $7[5,6]$.

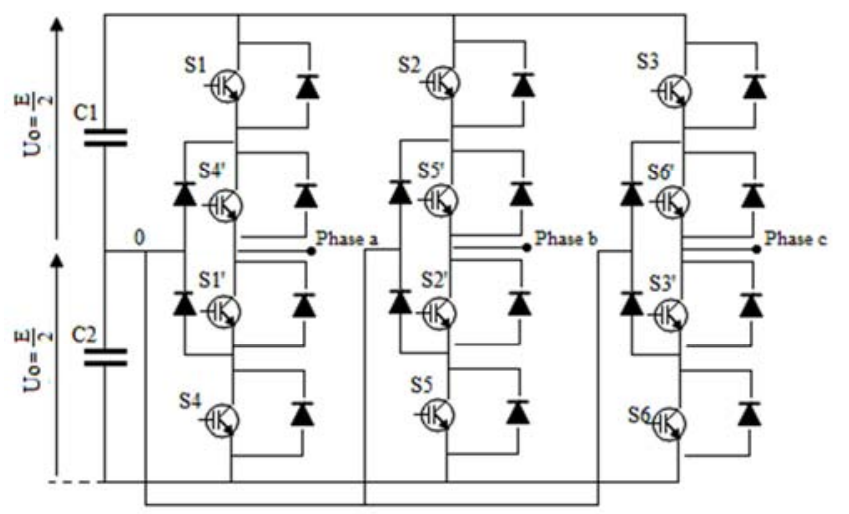

Figure 7. Structure of the NPC inverter.

It is composed of three half bridges single-phase. From the main source of tension continues $\mathrm{E}$, and using a capacitive voltage divider formed by the capacitors $\mathrm{C} 1$ and $\mathrm{C} 2$ with the same capacity, it gets two secondary sources of DC voltage, each one providing a potential to half voltage $\mathrm{E} / 2$. This structure creates a neutral point $\mathrm{O}$ between the capacitors $\mathrm{C} 1$ and $\mathrm{C} 2$. Each half is composed of two floors of switches. Each floor has two IGBT transistors in series with a common point connected by a diode to the neutral point O. Anti-parallel diodes on the transistors ensure reversibility of load currents.

\section{Meteorological Data from the Measurement Site}

The solar data necessary for the establishment of a system is the choice of radiation in the plane of the panels and the junction temperature of the cells, Figure 8 .

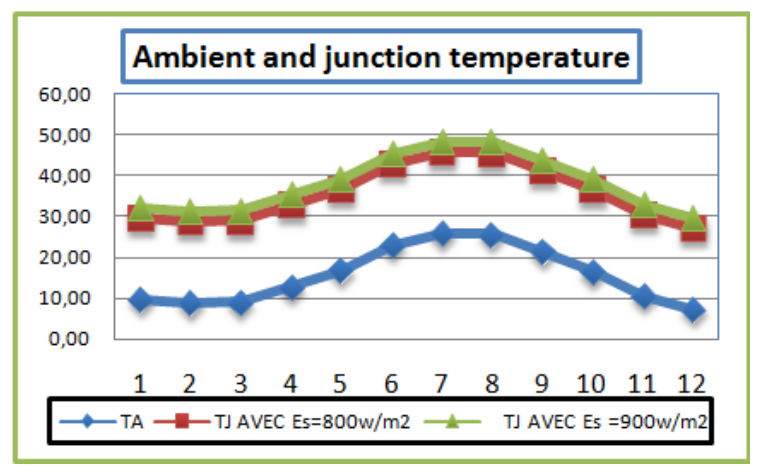

Figure 8. Junction temperature of the cells under different insolation.
The temperature of the panels; $\mathrm{Tj}$ is estimated from the data of sunshine and the temperature by the formula given by [7].

$$
T_{j}=T_{a}+E_{S} \cdot \frac{N_{o c t}-20}{800}
$$

$\mathrm{N}_{\text {oct }}$ : is the «nominal operating cell temperature», is a parameter supplied by the manufacturer of the solar panels. This model does not take into account the effects of the influence of wind on the heat exchange.

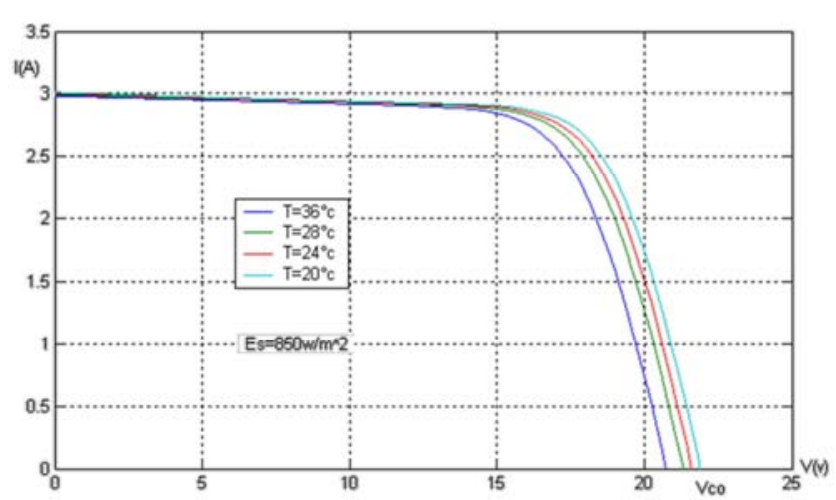

Figure 9. Influence of temperature on the characteristicI (V).

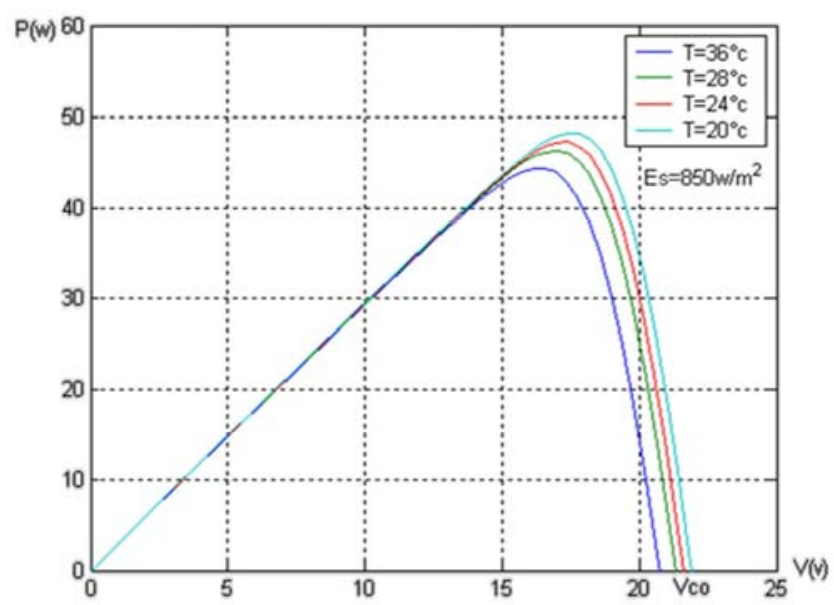

Figure 10. Influence of temperature on the characteristic $P(V)$.

When we vary the temperature, Figure 10 , of $25^{\circ} \mathrm{c}$ to $36^{\circ} \mathrm{c}$ at constant sunshine, Es $=850 \mathrm{w} / \mathrm{m}^{2}$, we note that the temperature is inversely proportional to the open circuit voltage: when the temperature increases, the open circuit voltage Voc decreases $[4,6]$.

\section{Determination of the voltage Drop a Line in the Presence of GPV}

The contribution of the voltage supplied by the photovoltaic system is the difference between the voltage drop $\Delta \mathrm{V}$ in line with and without GPV, the relationship of the voltage drop between the upstream network and the connection point of a PV system is determined as follows [8]. Each piece of power line is cut up into segments or dipoles where clients are 
distributed. Because in our study we considered that the behavior of a line to the energy transfer can be assimilated, under certain conditions [9], to that of the model figure 11.

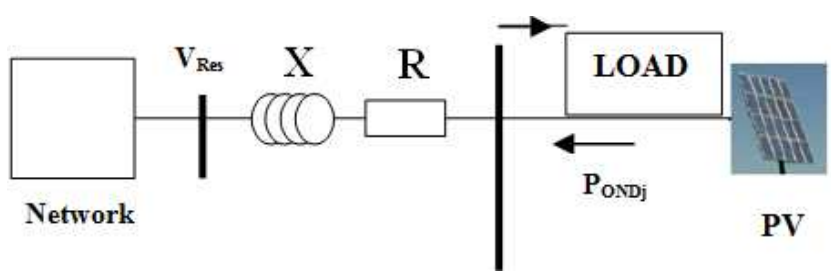

Figure 11. Model of a short line.
The relative voltage drop (\%) of the dipole (n) equals:

$$
\left(\frac{\Delta U}{U}\right)_{n}=1+10^{5}\left[\frac{R+X \operatorname{tg} \varphi}{U^{2}}\right] \cdot \sum_{i=1}^{n}\left(P_{i} \cdot L_{i}\right)
$$

R: Linear resistance of a conductor $(\Omega / \mathrm{Km}) \mathrm{X}$ : linear reactance of a conductor $(\Omega / \mathrm{Km})$

$P_{i}=\sum_{j=1}^{n}\left(P_{j}-P_{O N D j}\right)$ Cumulative power drawn by the load (kW). Li Dipole length.

$P_{O N D j}:$ The inverter output power $(\mathrm{kW})$ on the dipole $\mathrm{j}$.

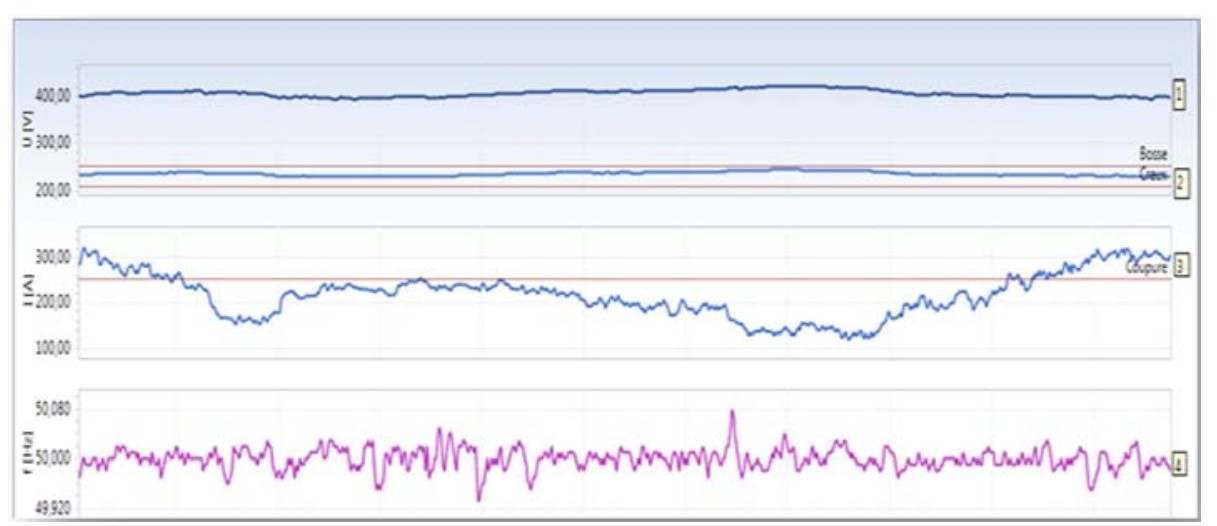

Figure 12. Network characteristics: (1) composed voltage. (2) Single Voltage. (3) Current characteristic. (4) Oscillation frequency.

\section{Results and Analysis}

To illustrate the experimental results of the proposed approach derived from a BT network, first, the measurements are made by the meter model METREL power Q4. The first surveys characterize the behavior of the transformer station figure 12 .

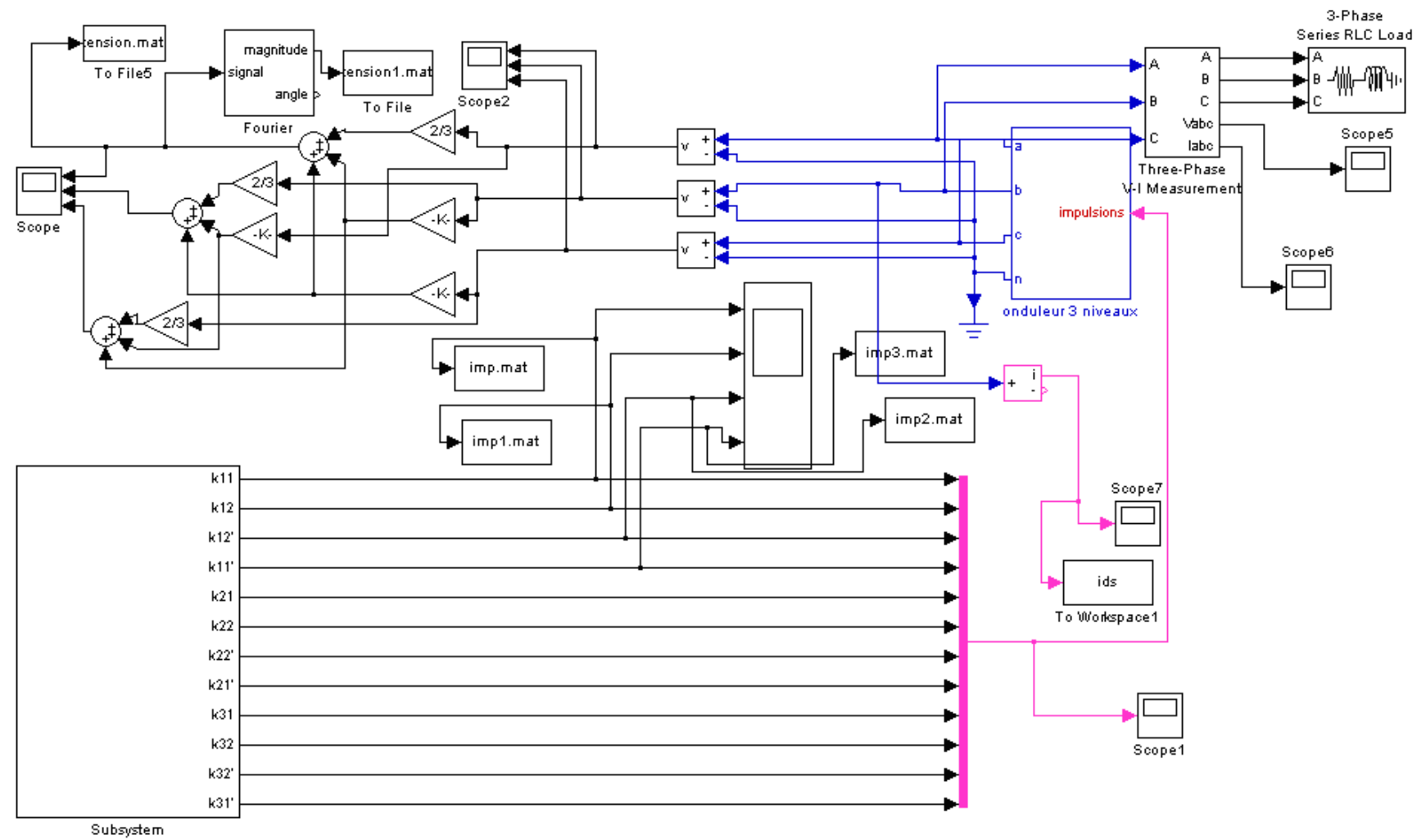

Figure 13. Block diagram of the energy conversion system. 


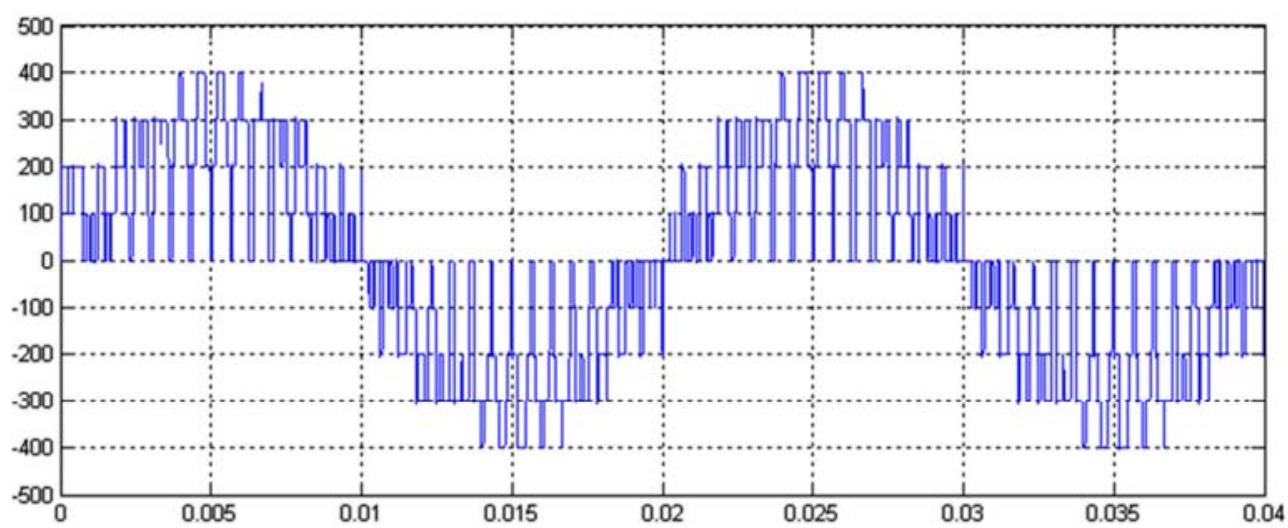

(a) Temps(s)

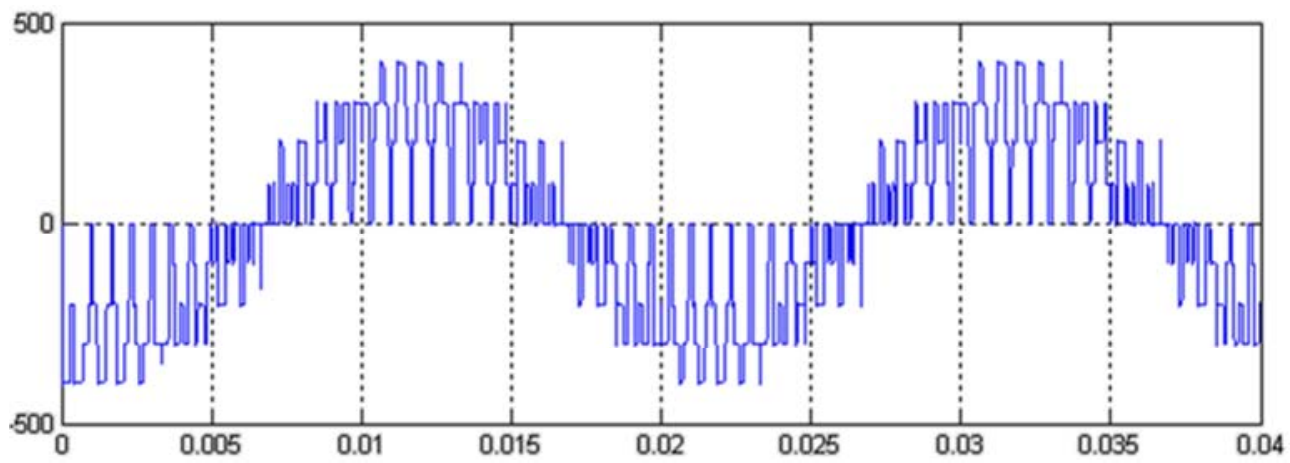

(b) Temps(s)

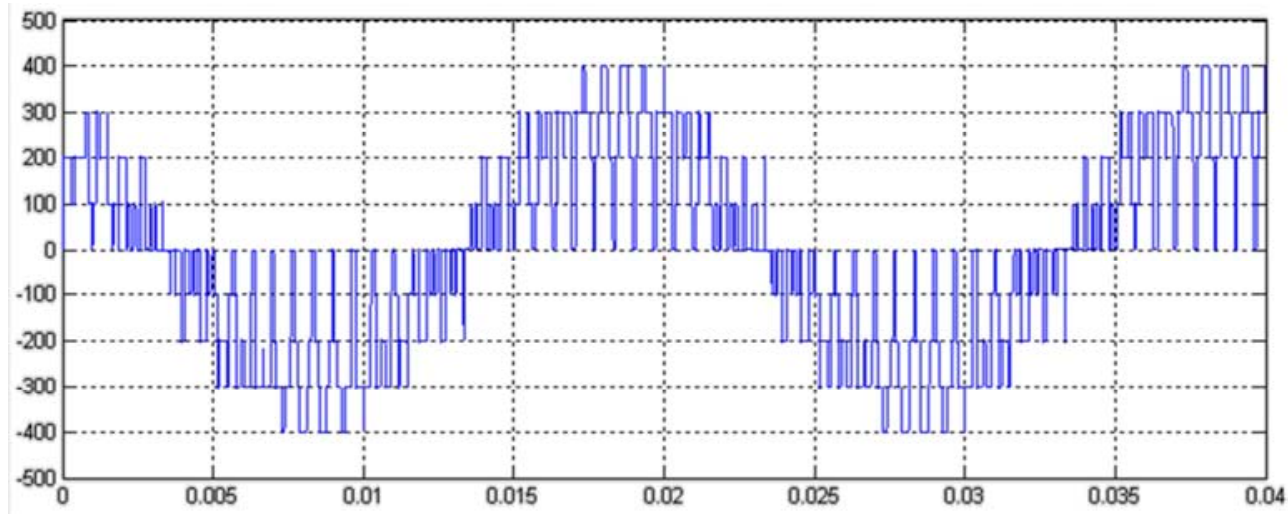

(c) Temps(s)

Figure 14. Allure of the system output voltages: (a) Composed VAB voltage. (b) Composed VBC voltage. (c) Composed voltage VCA.

We note that the inverter (NPC) requires a system to its output voltages that are not synchronized with the system voltages figure 14 . These static and dynamic performance are very interesting and these applications are different nowadays especially in the area of renewable energy in low voltage applications.

Figures $16 ; 17 ; 18 ; 19$ show the energy gain by making the insertion of GPV in 1 and 2 departures BT network used, although the voltage drop is noted to exceed allowable limits $13.76 \%$ for the departure $\mathrm{N}^{\circ} 1$ and $14.81 \%$ for the departure $\mathrm{N}^{\circ} 2$, considerably reducing the long lines, and also revealing that in all branches of the lines, the voltage is increased to the allowable limits.

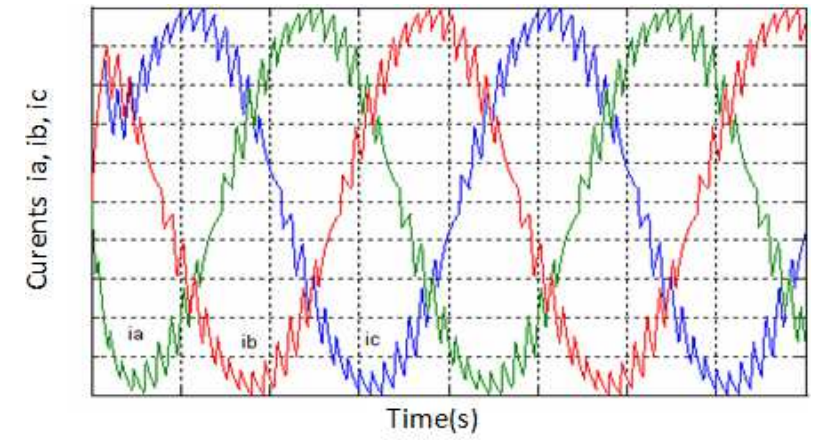

Figure 15. Phase current of the PV system. 
To departure $\mathrm{N}^{\circ} 1$, two injections were made at the same time, the first to the node 22 and the second to the node 27 to bring the voltages drops below $10 \%$. The orca injections made separately voltage drops reduction problem unsolved.

Injection at node 22 figure 16.

The initial maximum voltage drop which is $13.76 \%$ in the node 22 is decreased significantly to the value of $9.18 \%$ in the same node, by against values exceed allowable limits are registered in other nodes, the maximum value of the voltage drop $13.70 \%$, seen in node 27 .

Injection at node 27 figure 17.
Almost the same is found for injection at node 27, the maximum voltage drop of $13.76 \%$ it remained stationary without change, against the voltage drop at node 27 was $13.70 \%$ became $8.53 \%$.

Injection at nodes 22 and 27 figure 18.

The conclusion here is different, as the voltage drop across all nodes is reduced, and the maximum value recorded $9.45 \%$ in node 18 . For departure $\mathrm{N}^{\circ} 2$, the maximum voltage drop recorded is $14.81 \%$ after injection made at node 18 , the voltage drops are dropped along the departure, the maximum observed value is $9.11 \%$ in node 14, Figure 19.

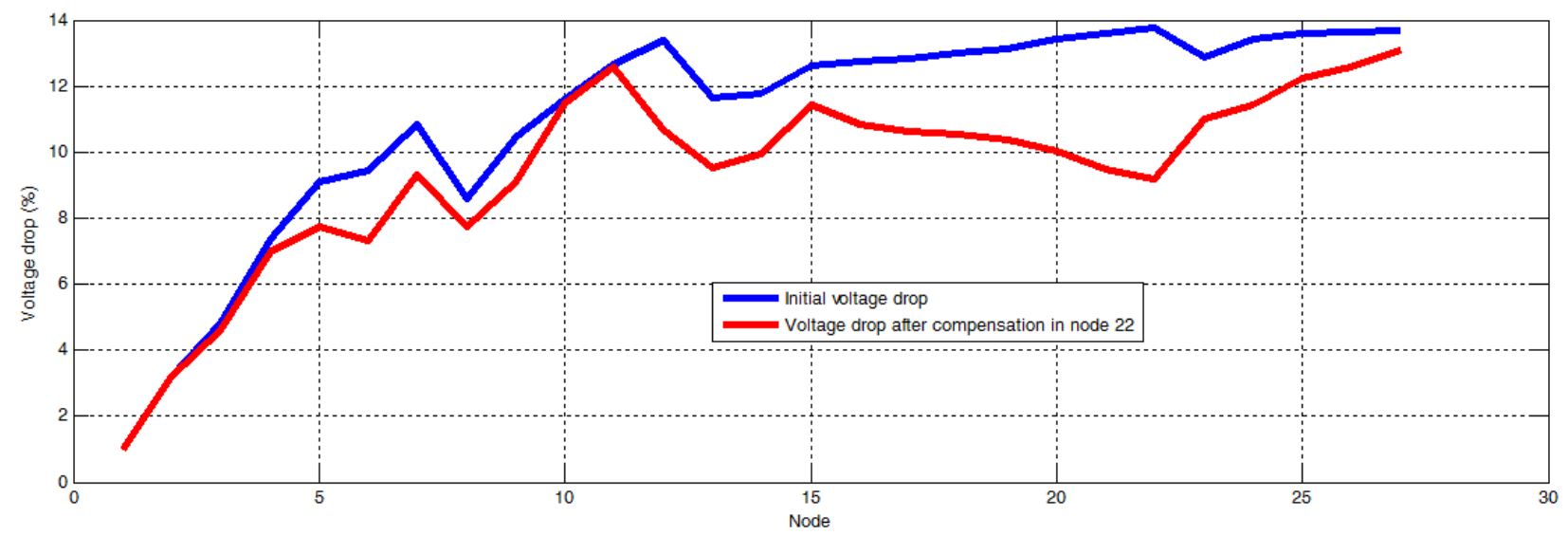

Figure 16. Voltage drops of departure $N^{\circ} 1$ after compensation in node 22.

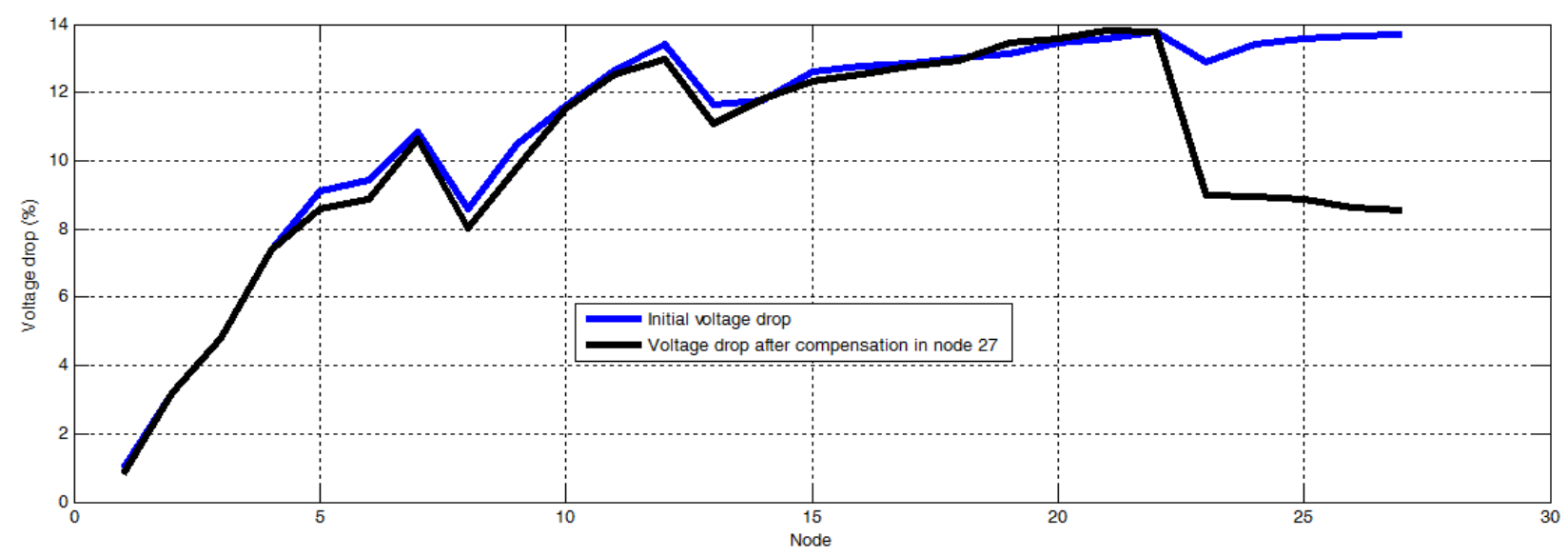

Figure 17. Voltage drops of departure $N^{\circ} 1$ after compensation in node 27.

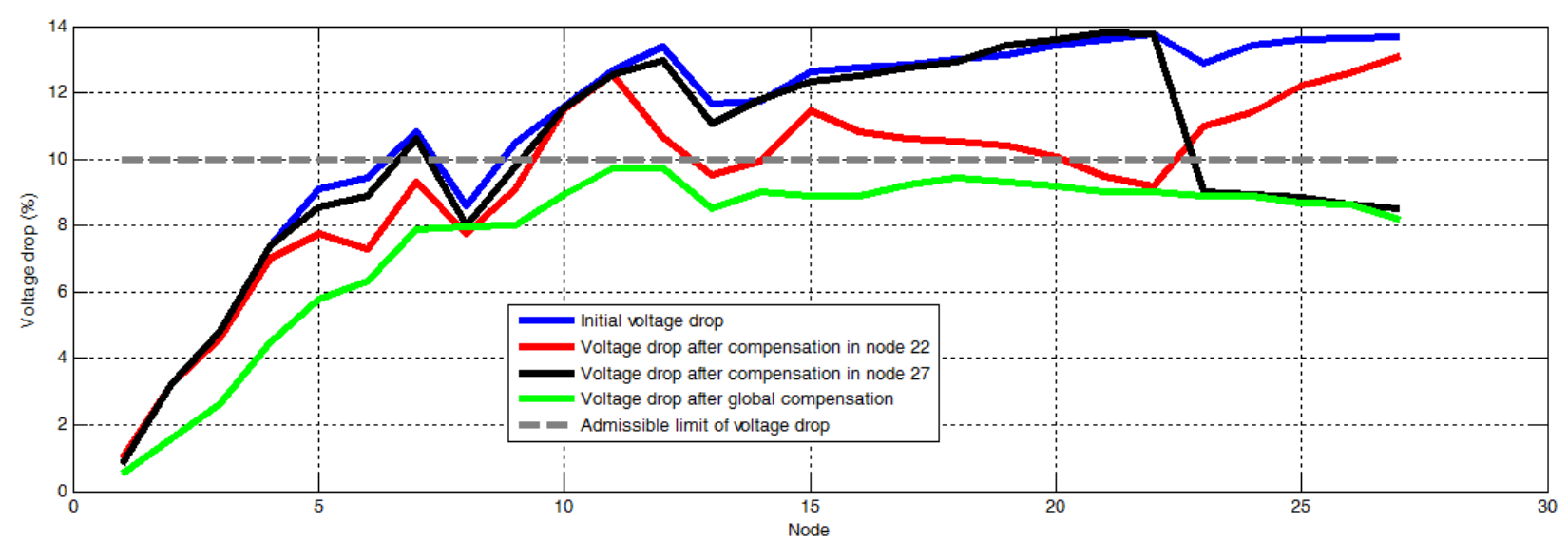

Figure 18. Voltage drops of departure $N^{\circ} 1$ after global compensation. 


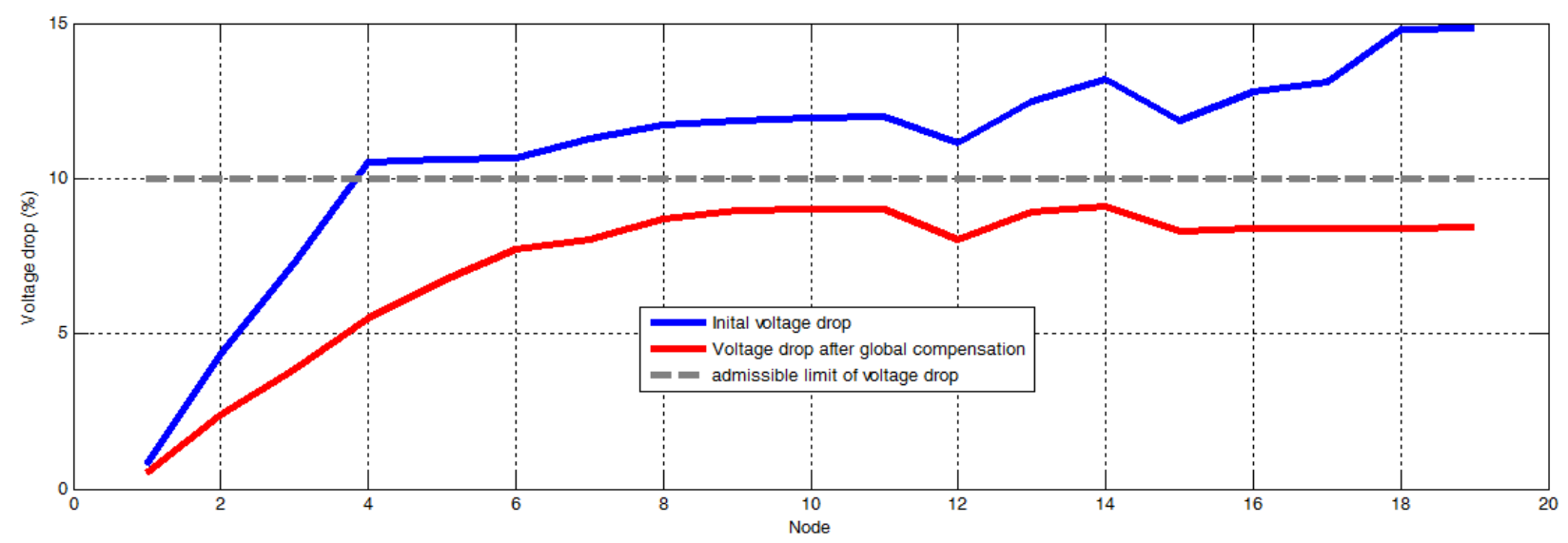

Figure 19. Voltage drops of departure $N^{\circ} 2$ after global compensation.

Photovoltaic installations, closer to places of consumption would reduce losses and contributes to decreased energy transit in low voltage networks, as several studies have been made show that in a community that focuses more photovoltaic installations, the injection of energy on the network increased the voltage to a threshold causing the decoupling of some systems.

To justify our study, an analysis at the residential level was made, in order to measure the customer satisfaction at the tip of the low voltage network which represents a real technical challenge for energy distributors. For this we have raised the voltage drops from one client to the starting end departure $\mathrm{N}^{\circ}$ 2. In Figure 20, we present the consumption profile of a customer in the course of a day, which has subscribed a power of $6 \mathrm{kva}$, and then we studied the impact of the connection of the photovoltaic energy on the improving the quality of energy supplied to the user.
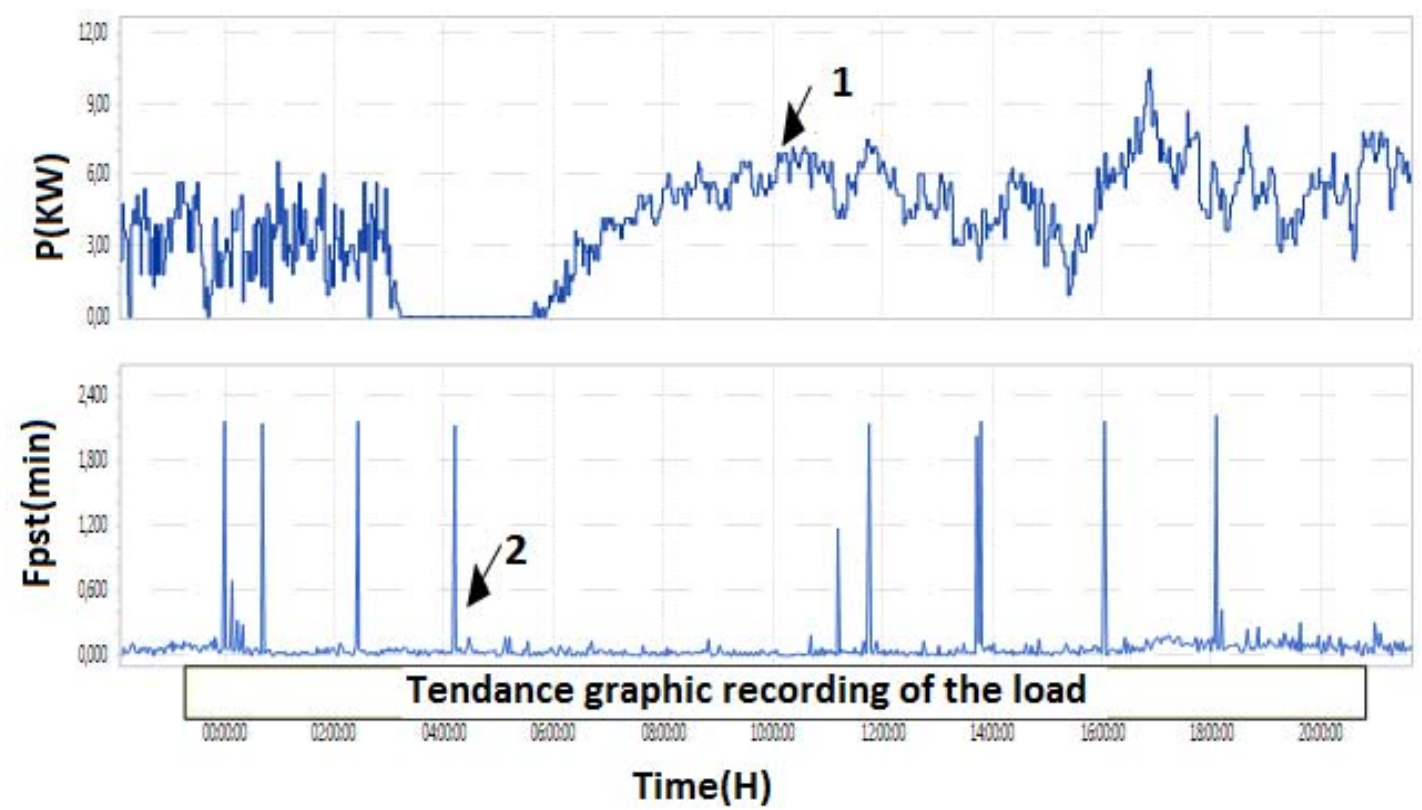

Figure 20. (1): Consumption profile (2): Flicker.

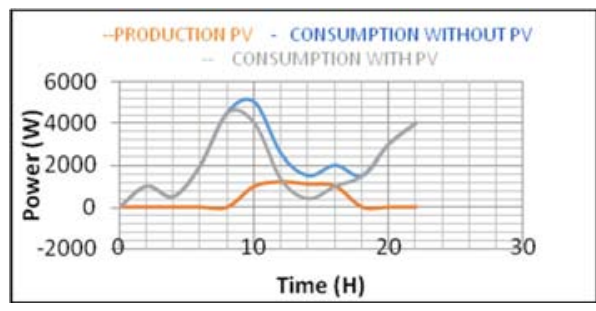

Figure 21. Reduced consumption with PV.

The peak observed by this consumer is at 12 o'clock, as PV production helps mitigate this advanced system with almost 1
$\mathrm{kW}$, Figure 21. So we can confirm that the installations PV to the residential scale reduced locally transts power in a LV network. The client can safely use the appliances (air conditioning, refrigeration, washing machine... etc.).

\section{Conclusion}

We conclude that the integration of photovoltaic systems in a low-voltage network helps improve the technical parameters (voltage, current) of the latter and can reduce energy transit. In addition, the use of BT network connected photovoltaic 
systems as a means of electrical energy compensation proves to be a highly feasible solution for network managers to be fully engaged in this approach.

The integration of photovoltaic systems can limit harm from conventional energy environment, to clip the load and avoid voltage drops during periods of high demand.

According to the study, the quality of the voltage at the ends of the network deteriorates when demand for electricity is increasing and installation of photovoltaic systems can help rectify the voltage and improve consumer comfort, assuring him a voltage suitable for performance of these appliances.

It's time to design LV networks, taking into account the future presence of PV systems in the processing of connection requests the areas of building gold, of commercial activity. If we disregard the hydroelectric potential, the contribution of renewables to our energy balance is negligible.

\section{References}

[1] Brambilla, A. Gambarara, M. Garutti, A and Ronchi, F: New approach to photovoltaic arrays maximum power point tracking. Power electronics specialists conference, 30th Annual IEEE (1999), Vol. 2, 1999. p. 632-637.

[2] Kasemsan, S. Caliskan, V. and Lee C. Q.: Maximum power tracking in parallel connected converters, IEEE transactions on aerospace and electronics systems (1993), Vol. 29, №3. 1993.

[3] Muselli, A. Notton, G. Louche, A.: Design of hybrid-photovoltaic power generator, with optimization of energy management, solar energy, Elsevier (1999), Vol. 65, 1999. p. 143-157.
[4] Bae, H. S. Park, J. H. Cho, B. H. and Yu G. J.: New control strategy for 2-stage utility-connected photovoltaic power conditioning system with a low cost digital processor, Power electronics specialists conference, IEEE (2005), 2005. p. 29252929.

[5] Zainudin, H. N. S. Mekhilef, Comparison study of maximum power point tracker, Techniques for PV systems. Proceedings of the 14th international middle east power systems. Conference (MEPCON'10), Cairo University, Egypt, 2010. p. 19-21.

[6] Petrone, G. Spagnuolo, G. Vitelli, M. A.: Multivariable perturband observe maximum power point tracking technique applied to a singlestage photovoltaic inverter. IEEE Trans. Ind. Electron (2011). Vol. 58, No.1, p.76-84.

[7] Rahmani, S. Hamadi, A. Al-Haddad, K. Kanaan, H. Y.: Amulti functional power flow controller for photovoltaic generation systems with compliance to power quality standards, 38th Annual Conference on EEE Industrial Electronics Society IECON (2012), p. 894 - 903, 2012.

[8] Ueda, Y.: Analytical results of output restriction due to the voltage increasing of Power distribution line in grid-connected clustered PV systems, 31st IEEE Photovoltaic Specialists Conference, 2005.

[9] Ueda, Y.: performance analyses of battery integrated grid-connected residential Systems. 21st European PVSEC, 4-8 September 2006, Dresden, Germany.

[10] Kazutaka I, and Takeaki M.: ACurrent Sensor less MPPT Control Method for a Stand-Alone-Type PV Generation System, Electrical Engineering in Japan, Vol. 157, N², pp. 65 71, 17 Aug 2006. 